\title{
Synthesis and Characterization of Bionanoparticle-Silica Composites and Mesoporous Silica with Large Pores
}

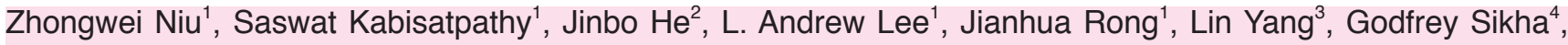 \\ Branko N. Popov ${ }^{4}$, Todd S. Emrick ${ }^{2}$, Thomas P. Russell' ${ }^{2}$, and Qian Wang ${ }^{1}(\bowtie)$ \\ ${ }^{1}$ Department of Chemistry and Biochemistry and Nanocenter, University of South Carolina, Columbia, SC 29208, USA \\ ${ }^{2}$ Department of Polymer Science and Engineering, University of Massachusetts, Amherst, MA 01003, USA \\ ${ }^{3}$ Brookhaven National Laboratory, Upton, NY 11973, USA \\ ${ }^{4}$ Department of Chemical Engineering, University of South Carolina, Columbia, SC 29208, USA \\ Received: 21 December 2008/Revised: 15 March 2009/Accepted: 24 March 2009 \\ (C) Tsinghua University Press and Springer-Verlag 2009. This article is published with open access at Springerlink.com
}

\begin{abstract}
A sol-gel process has been developed to incorporate bionanoparticles, such as turnip yellow mosaic virus, cowpea mosaic virus, tobacco mosaic virus, and ferritin into silica, while maintaining the integrity and morphology of the particles. The structures of the resulting materials were characterized by transmission electron microscopy, small angle $\mathrm{X}$-ray scattering, and $\mathrm{N}_{2}$ adsorption-desorption analysis. The results show that the shape and surface morphology of the bionanoparticles are largely preserved after being embedded into silica. After removal of the bionanoparticles by calcination, mesoporous silica with monodisperse pores, having the shape and surface morphology of the bionanoparticles replicated inside the silica, was produced,. This study is expected to lead to both functional composite materials and mesoporous silica with structurally welldefined large pores.
\end{abstract}

\section{KEYWORDS}

Mesoporous silica, bionanoparticles, virus, ferritin, sol-gel

\section{Introduction}

Mesoporous silica has attracted increasing interest recently for applications including separations, catalysis, sensing, and biotechnology [1-4]. Many synthetic pathways have been reported for the preparation of porous silica using a variety of templates. In particular, syntheses of ordered mesoporous silica materials have been developed using liquid crystalline phases of ionic surfactants and amphiphilic block copolymers as templates
[1, 5-10]. Ordered mesoporous materials with pore size larger than $12 \mathrm{~nm}$ are in demand for use in both reactions and separations $[4,6,11,12]$. On the other hand, nature employs protein assemblies, such as viruses and virus-like particles [13, 14], ferritins [15, 16], heat shock protein cages [17], and enzyme complexes [18-20] to form vital biosynthetic machineries. These protein shells, or bionanoparticles (BNPs), are highly organized nanoscale materials with robust chemical and physical properties while being amenable to modification using genetic

Address correspondence to wang@mail.chem.sc.edu 
or chemical methods. A myriad of viruses and other BNPs have been genetically and chemically reprogrammed to function as drug/gene delivery vehicles [14, 21-23], vaccines [23-25], nanowires [26-28], cell-culturing scaffolds [29, 30], and composite materials [27, 31-35]. Most BNPs possess outstanding thermal and $\mathrm{pH}$ stabilities along with tremendous resistance to denaturation at high ionic concentrations. Such features, in combination with superb symmetry and size uniformity, make BNPs unique templates for the synthesis of mesoporous materials.

In the literatures, proteins, enzyme, and ferritins have been reported to be capable of encapsulation in a sol-gel derived silica glass [36-39]. For example, Tartaj and coworkers showed that an aerosol-based process led to colloidal composites containing metallic nanomagnets with reconstituted apoferritins as nanocarriers [40], Mann and coworkers reported the use of the nematic phase of tobacco mosaic virus (TMV) assemblies as templates for mesostructured silica [41], and Royston et al. demonstrated that silica could be coated onto the surface of TMV under basic conditions [42]. Yet, it remains a challenge to develop a practical sol-gel protocol using biological entities as templates, while preserving the shape and surface features of the templates. In this work, a practical and versatile sol-gel process for incorporation of BNPs into silica, which maintains the integrity and morphology of the particles, is reported. The results showed that the shape of the bioparticles can be imprinted into mesoporous.

Four BNPs were employed in this study, namely turnip yellow mosaic virus (TYMV), cowpea mosaic virus (CPMV), TMV, and horse spleen ferritin (HSF), as shown in Fig. 1. TYMV is a non-enveloped plant virus composed of 180 identical protein subunits (20 kDa), assembled loosely in a $T=3$ icosahedral symmetry. The capsid consists of 32 knob-like structures corresponding to 20 hexamers and 12 pentamers of the coat protein (Figs. 1(d) and 1(e)) [43, 44]. CPMV is also a plant virus and can be obtained from infected cowpea plants. The physical, biological, and genetic properties have been well characterized over the past few years [45-48]. It is composed of 60 copies of two protein submits in an icosahedral symmetry. CPMV has a similar diameter to TYMV, i.e., $\sim 30 \mathrm{~nm}$; however, the surface features are quite different. TMV consists of 2130 identical protein subunits arranged in a helical motif around a single

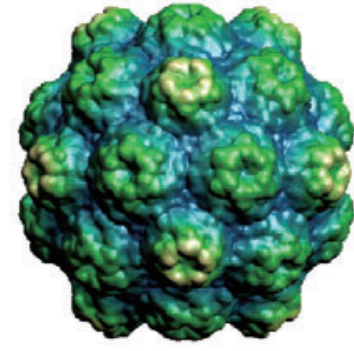

(a)

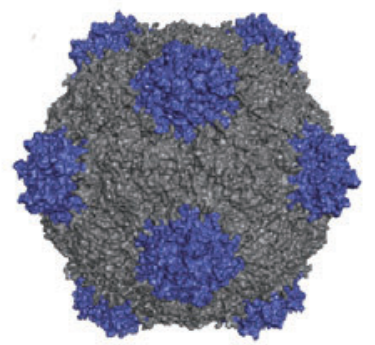

(b)

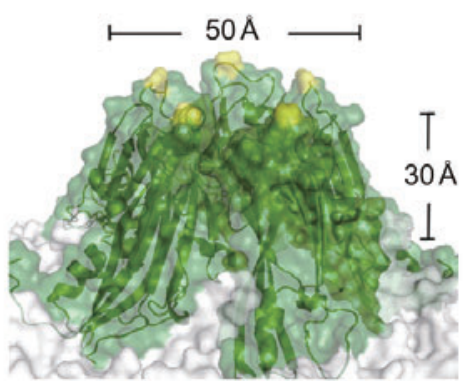

(e)

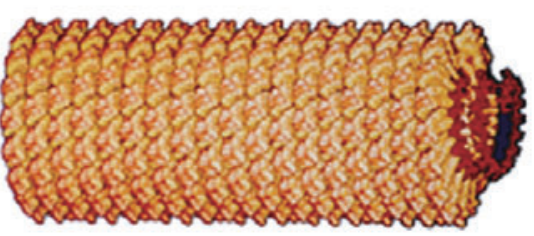

(c)

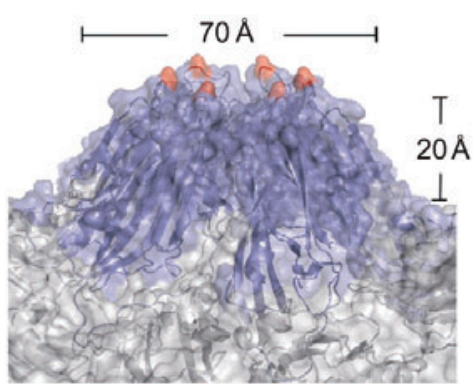

(f)

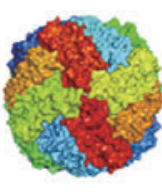

(d)

Figure 1 X-ray crystal structure of (a) TYMV, (b) CPMV, (c) TMV, and (d) HSF. (e) and (f) show the structures and dimensions of the exterior view of the pentameric and hexameric units of TYMV which appear as knob-like protrusions. Structures were generated using PyMol (www.pymol. org) with coordinates from the RCSB Protein Data Bank (www.pdb.org) 
RNA strand to produce a hollow protein rod [49]. This rod-like, 18-nm diameter virus is $\sim 300 \mathrm{~nm}$ in length and exhibits remarkable stability, remaining intact at temperatures up to $60{ }^{\circ} \mathrm{C}$ and at $\mathrm{pH}$ values between 2 and 10 [50]. The surface functionality and the rod-like nature of TMV, which gives rise to characteristic self-assemblies, have been widely exploited for materials development [41, 50-56]. HSF, a smaller protein assembly with a 6-nm iron core, has been used to encapsulate a variety of metal oxides through a bio-mimetic pathway $[57,58]$.

\section{Experimental}

Purification of viruses. Wild type TMV (wt-TMV) was obtained from tobacco plants. Tobacco plants approximately 1 month old were inoculated with wt-TMV. The leaves were harvested and the virus was isolated from the host plant. The leaves were crushed and blended with $0.01 \mathrm{~mol} / \mathrm{L}$ K-phosphate buffer at $\mathrm{pH} 7.8$ with $0.2 \% \quad \beta$-mercaptoethanol. The mixture was centrifuged at $9000 \mathrm{rpm}$ for $15 \mathrm{~min}$ after which the supernatant was clarified with 1:1 $\mathrm{CHCl}_{3}$ :1-butanol. The aqueous portion was separated by centrifugation and TMV was precipitated by the addition of polyethylene glycol (PEG $8 \mathrm{~K}$ ) to give a final concentration of $10 \%$ and $\mathrm{NaCl}$ to give a final concentration of $0.2 \mathrm{~mol} / \mathrm{L}$. The resulting pellet was resuspended in $0.01 \mathrm{~mol} / \mathrm{L} \mathrm{K}$-phosphate buffer at $\mathrm{pH}$ 7.8. After a final round of ultracentrifugation at $42,000 \mathrm{rpm}$ for $2.5 \mathrm{~h}$ using a Beckman Optima ${ }^{\mathrm{TM}}$ L-90K ultracentrifuge equipped with 50.2 Ti rotor, the resulting pellet was resuspended overnight in $0.01 \mathrm{~mol} / \mathrm{L} \mathrm{K}$-phosphate buffer at $\mathrm{pH} 7.8$ or in pure water. TYMV and CPMV were obtained from infected Chinese cabbage plants and cowpea plants, respectively, using a similar protocol to that used in purification of TMV. HSF was purchased from SigmaAldrich.

Synthesis of cobalt apoferritin [59]. HSF was demineralized with thioglycolic acid to make apoferritin, and the protein concentration was determined using the biuret method. An apoferritin solution (5 $\mathrm{mg}$ in $0.1 \mathrm{~mol} / \mathrm{L} \mathrm{NaCl}$ solution) was adjusted to $\mathrm{pH} 8.5$ with $0.01 \mathrm{~mol} / \mathrm{L} \mathrm{NaOH}$, and aliquots of $\mathrm{Co}\left(\mathrm{NO}_{3}\right)_{2}(25 \mathrm{mmol} / \mathrm{L}, 50 \mu \mathrm{L})$ were added, followed by addition of $\mathrm{H}_{2} \mathrm{O}_{2}(3 \%, 23.3 \mu \mathrm{L}$, $0.07 \mathrm{mmol}$ ) over a $2 \mathrm{~h}$ period with $10 \mathrm{~min}$ intervals between additions. A theoretical loading of $\sim 2000$ Co atoms per ferritin molecule was achieved by 18 addition cycles. The reaction was run unbuffered at $\mathrm{pH} 8.5$.

Sol-gel process. In a typical experiment, a presol was prepared by refluxing a mixture of the silica precursor, tetraethyl orthosilicate (TEOS) and an aqueous ethanol solution under weakly acidic conditions. TEOS (10 g), ethanol $(9.1 \mathrm{~g}), \mathrm{H}_{2} \mathrm{O}(7 \mathrm{~mL})$ and $2 \mathrm{~mol} / \mathrm{L} \mathrm{HCl}(200 \mu \mathrm{L})$ were refluxed for $1 \mathrm{~h}$ before aging at room temperature overnight. In order to make BNP/silica composites, previously prepared BNP solutions (varying concentrations) were used. For a $2 \mathrm{~mL}$ reaction, silica sol $(600 \mu \mathrm{L})$ was mixed with the BNP solution $(1400 \mu \mathrm{L})$ in a small glass vial for 1-2 min with stirring at room temperature. The solution was then coated onto a microscope glass slide and allowed to dry overnight. To obtain mesoporous silica, the dry samples were placed in a calcination vessel and calcined in an oven for $14 \mathrm{~h}$ (temperature ramping from 25 to $500{ }^{\circ} \mathrm{C}$ over $2 \mathrm{~h}$, at $500{ }^{\circ} \mathrm{C}$ for $2 \mathrm{~h}$, and then cooled down slowly to $25^{\circ} \mathrm{C}$ over $2 \mathrm{~h}$ and left to cool for a further $8 \mathrm{~h}$ ). The sample was then removed from the oven and stored for analysis.

Characterization. The morphology of the silica/virus composites and mesoporous silica was characterized using transmission electron microscopy (TEM) (Hitachi H-8000, operated at an accelerating voltage of $200 \mathrm{kV}$ ). The porosity of the mesoporous silica was measured by a nitrogen sorption technique (Quantachrome Corporation, NOVA 2000). Specific surface area was determined using the BET equation. The small angle X-ray scattering (SAXS) data were obtained at beamline X21 of the National Synchrotron Light Source, Brookhaven National Laboratory. The elemental composition was analyzed by scanning electron microscopy energy dispersive angle X-ray analysis (SEM-EDAX, Quanta 200).

\section{Results and discussion}

In our initial attempt, we found that it was difficult to obtain a homogeneous distribution of BNPs in 
silica following the literature method [41]. Our optimized protocol involves the preparation of pre-sol under weakly acidic conditions followed by mixing with the BNP solution (see Experimental section). As shown in the TEM image in Fig. 2(a), using this process, TYMV can be successfully incorporated in silica, with most of the virus particles retaining their original size and morphology as confirmed by TEM. After calcination at $500{ }^{\circ} \mathrm{C}$ for $2 \mathrm{~h}$, mesoporous silica was obtained, as shown by TEM (Fig. 2(b)). The $\mathrm{N}_{2}$ adsorptiondesorption isotherms of the mesoporous silica powders showed typical Type IV curves with a large hysteresis (Fig. 2(c)). This type of isotherm is characteristic of an open interpenetrating pore system with a cage structure $[6,60]$. The calcined sample had a $\mathrm{N}_{2}$ Brunauer-Emmett-Teller (BET) surface area of $635 \mathrm{~m}^{2} / \mathrm{g}$ when $20 \mathrm{mg} / \mathrm{mL}$ of TYMV was used as the template, which is comparable to mesoporous silica having large pores templated by a block copolymer [11, 12]. Although increasing the concentration of TYMV will likely augment the specific surface area, it is difficult to get a virus solution with much higher viral concentration. The most concentrated TYMV solution we could obtain without seeing obvious aggregation and precipitation was $\sim 30 \mathrm{mg} / \mathrm{mL}$. Considering that the average diameter of TYMV is $28 \mathrm{~nm}$, we surmise that the surface knob-like structures of TYMV make a major contribution to the large surface area of the resultant mesoporous silica (Figs. 1(d) and 1(e)).

SAXS is a fundamental and powerful tool for structure analysis of condensed matter [61]. It provides useful insights into the structure of non-crystalline biochemical systems. Moreover, SAXS also makes it possible to investigate intermolecular interactions including assembly and structure change. In particular, synchrotron

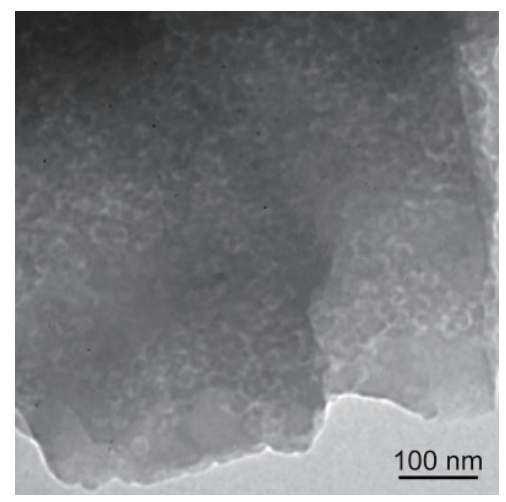

(a)

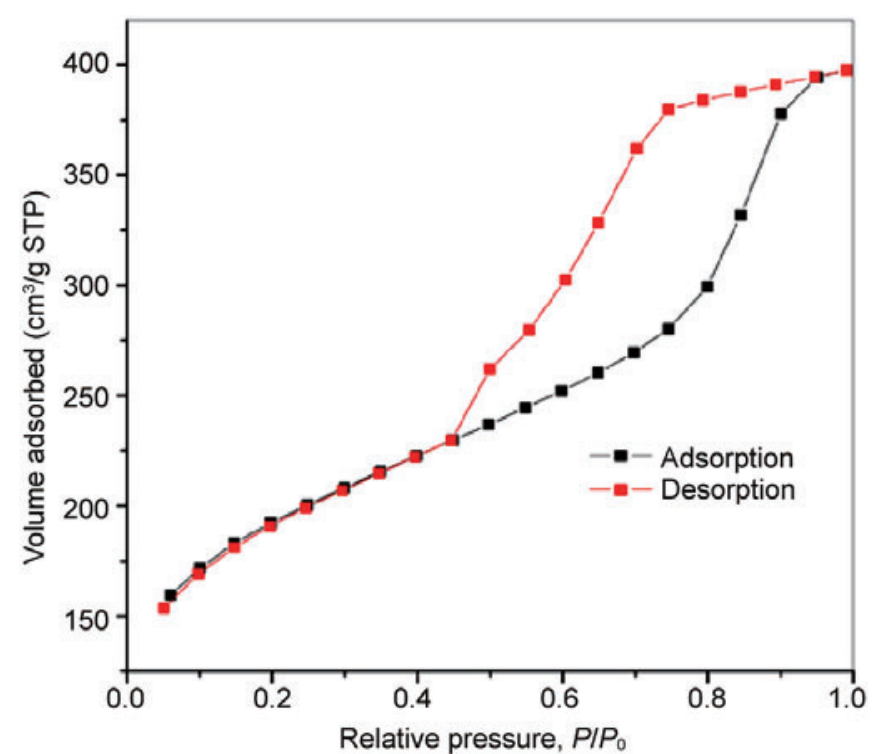

(c)

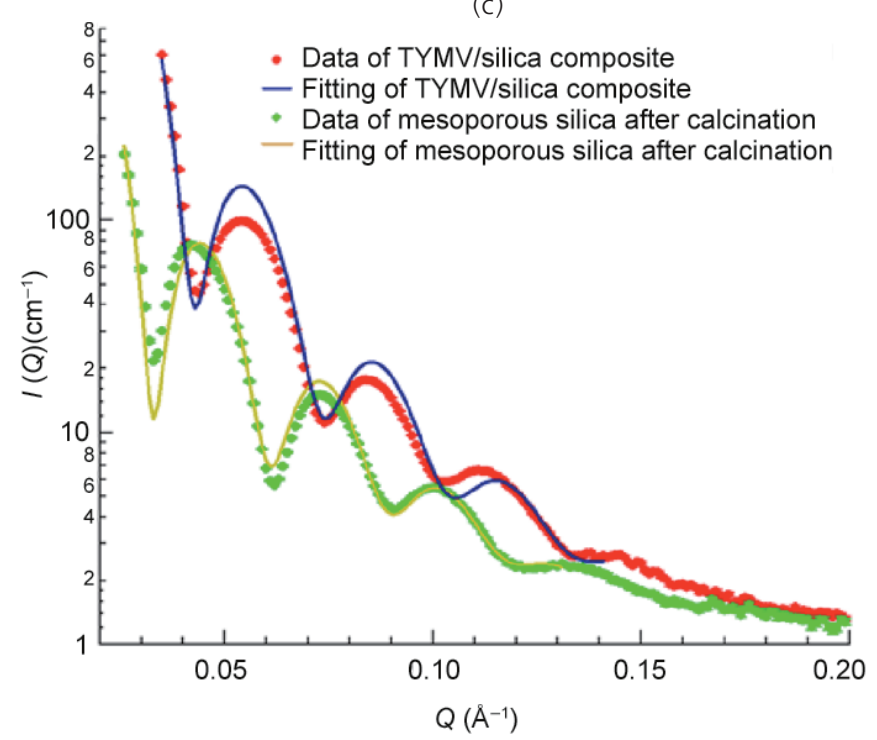

(d)

Figure 2 TEM images of (a) TYMV/silica composite; (b) mesoporous silica obtained after removal of TYMV by calcination at $500{ }^{\circ} \mathrm{C}$ for $2 \mathrm{~h}$; (c) nitrogen adsorptiondesorption isotherms for TYMV-templated mesoporous silica; (d) SAXS data of TYMV/silica composite and mesoporous silica obtained after removal of TYMV by calcination

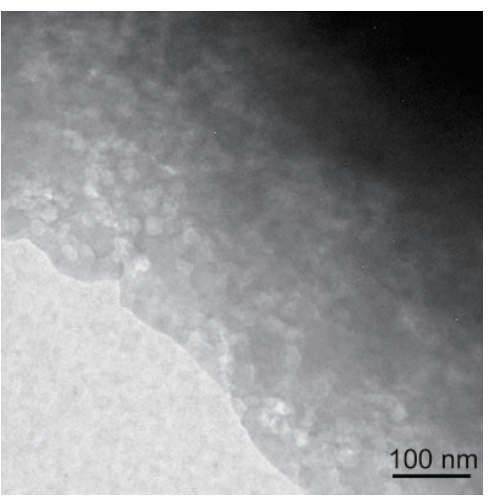

(b)

. 
SAXS is an effective method for the quantitative analysis of bionanoparticle structures [26, 34, 35]. To determine whether TYMV retains its original morphology, SAXS was performed on the TYMV/ silica nanocomposite and the mesoporous silica obtained after removal of TYMV by calcination (Fig. 2(d)). For the TYMV/silica nanocomposite, model fits to the SAXS data gave an inner radius of $9.0 \mathrm{~nm}$ and a wall thickness of $2.5 \mathrm{~nm}$, indicating that TYMV embedded in silica retained its spherical shape. However, the SAXS data of the imbedded TYMV were slightly different from that in solution. Using the Schultz polydisperse core and spherical shell model, TYMV was found to have an inner radius of $10.1 \mathrm{~nm}$ and a wall thickness of $3.5 \mathrm{~nm}$, which is consistent with its X-ray crystallographic structure [44]. There is a large electron density difference between TYMV and silica, which produces a high intensity in the SAXS, enabling analysis of the interactions between viral particles and silica matrix. Assuming the protein skeleton was not deformed after the sol-gel process, the data suggested that the silica was not only formed on top of the exterior surface of TYMV, but also penetrated deeply into the coat proteins of the virus. In addition, the SAXS data showed that the pores generated after calcination were monodisperse with a diameter of $20.6 \mathrm{~nm}$. This further confirms that BNPs can be used as an effective template for the generation of mesoporous silica with a controlled pore shape and size.

Another spherical bionanoparticle, CPMV was also used to template the synthesis of mesoporous silica. TEM was used to image the CPMV-imbedded silica and the spherical shape of CPMV within the silica can be clearly observed (Fig. 3(a)). Similarly, CPMV was well dispersed in silica after the sol-gel process and subsequent calcination (Fig. 3(b)). After calcination, the $\mathrm{N}_{2}$ adsorption-desorption isotherm obtained showed typical Type IV curves with a large hysteresis (Fig. 3(c)), very similar to TYMV-templated mesoporous silica. The sample had a $\mathrm{N}_{2}$-BET surface area of $222 \mathrm{~m}^{2} / \mathrm{g}$, which is much less than that of the TYMV-templated mesoporous silica obtained using the same amount of virus template, i.e., $20 \mathrm{mg} / \mathrm{mL}$. This is very interesting considering that both CPMV and TYMV are similar in size and shape. As previously stated, the reason behind the variation may well result from the 32 knob-like structures located on the TYMV capsid which lead to much larger dynamic porosity in comparison with CPMV.

Since many studies have demonstrated that ferritin, another type of spherical BNP, can be used as a nanoreactor for the formation of metal or inorganic nanocrystals $[57,58]$, it was also used as a template for the sol-gel process. As shown in Fig. 4(a), when native HSF was used in the experiments, scanning electron microscopy-energy dispersive angle X-ray (SEM-EDAX) analysis indicated the presence of iron within the HSF-templated mesoporous silica. HSF can be easily converted into apoferritin, a protein shell without a mineral core, by reductive removal of

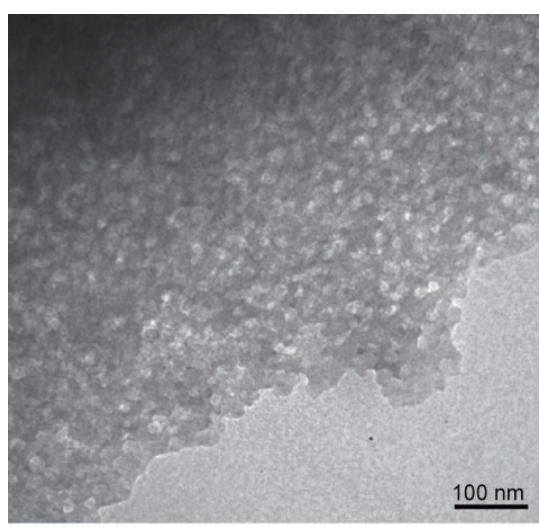

(a)

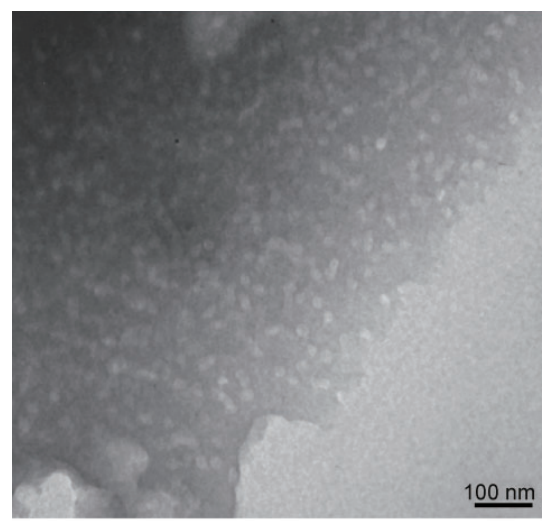

(b)

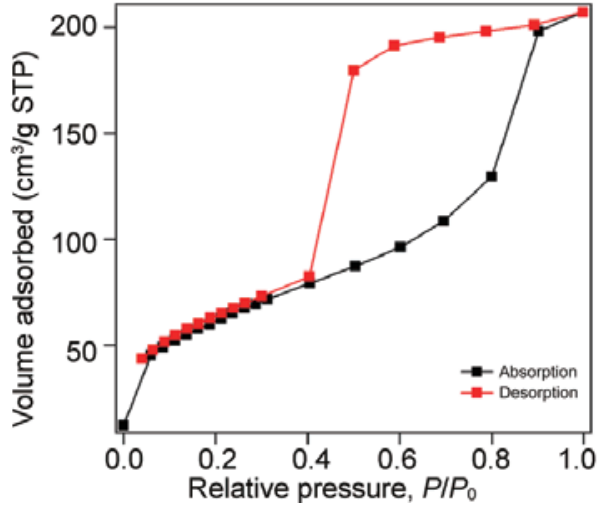

(c)

Figure 3 TEM images of (a) CPMV/silica composite, and (b) mesoporous silica obtained after removal of CPMV by calcination at $500{ }^{\circ} \mathrm{C}$ for $2 \mathrm{~h}$; (c) Nitrogen adsorption-desorption isotherms for TYMV templated mesoporous silica after removal of CPMV by calcination 


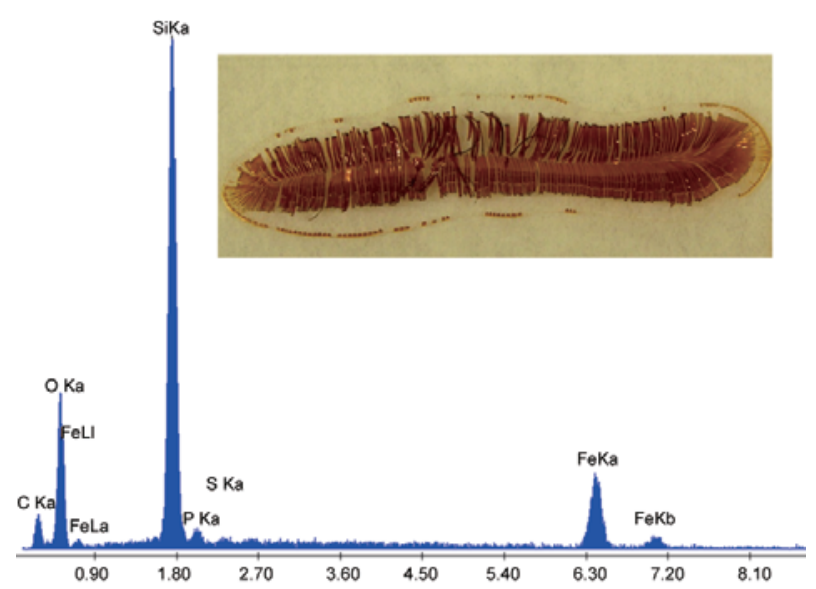

(a)

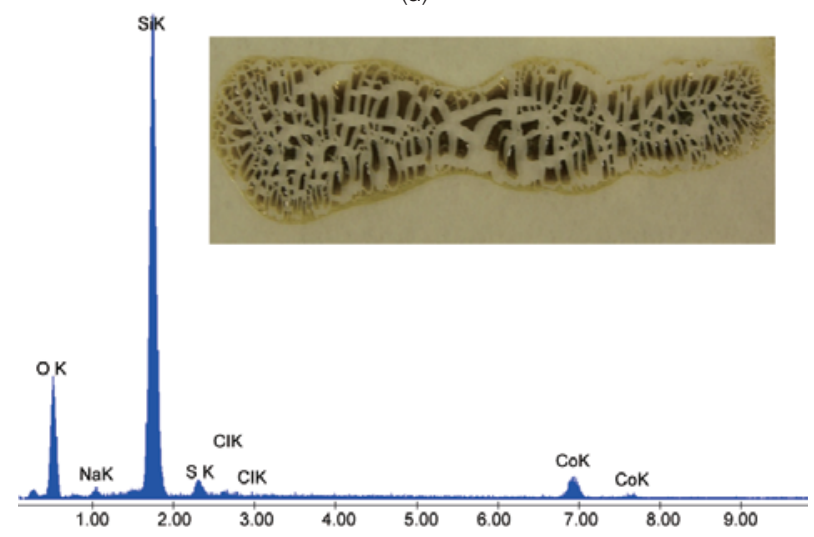

(b)

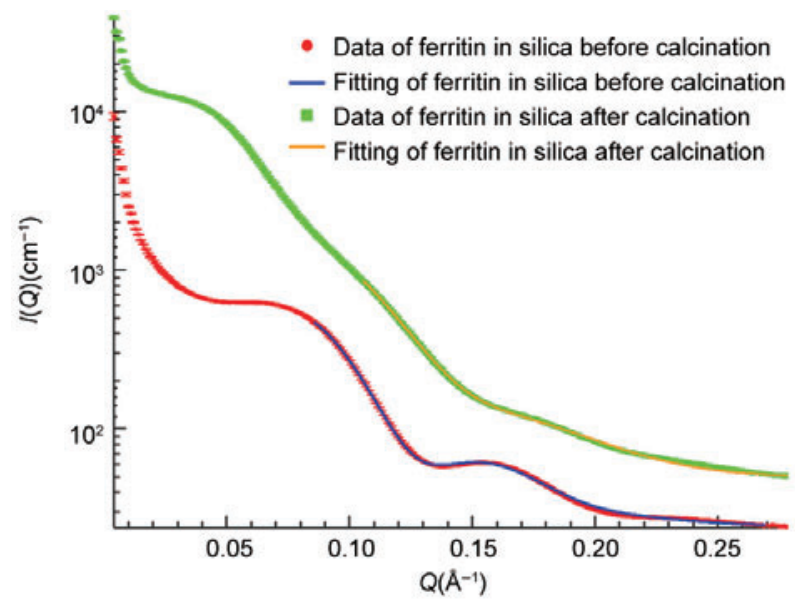

(c)

Figure 4 (a) EDAX data and optical images (inset) of the HSF/silica composite; (b) EDAX data and optical images (inset) of the CoAF/ silica composite; (c) SAXS data of the ferritin/silica composite and mesoporous silica after removal of ferritin by calcination. The data of the ferritin/silica composite were fitted with the Schultz polydisperse core and spherical shell form factor, which gave a core radius of 3.40 $\mathrm{nm}$, a shell $2.20 \mathrm{~nm}$ in thickness, with an rms core radius spread of $0.49 \mathrm{~nm}$. The data of mesoporous silica obtained after calcination were also fitted with the Schultz polydisperse core and spherical shell form factor, which gave a core radius of $2.71 \mathrm{~nm}$, a shell $2.21 \mathrm{~nm}$ in thickness, with an rms radius spread of $0.58 \mathrm{~nm}$ the iron oxide core. Once removed, a cobalt core can be inserted and a newly formed cobalt-apoferritin (CoAF) can be obtained [59]. We synthesized CoAF from HSF and used it in the same sol-gel process to obtain a CoAF/ silica composite (Fig. 4(b), inset). SEM-EDAX analysis showed that cobalt was homogeneously dispersed in the silica. SAXS data showed that after being embedded in silica, ferritin retained its original features (Fig. 4(c)). Therefore, this sol-gel process can potentially be used to fabricate mesoporous silica incorporated with a homogeneous distribution of inorganic oxides such as cobalt, which may lead to important applications in catalysis and electronics.

Additional versatility of this synthesis process was shown for the case of TMV, which when dispersed in the silica sol as a result of the sol-gel process, was found to retain its rod-like morphology, as shown in Fig. 5(a). Mann and coworkers used TMV in its nematic liquid crystal phase as a template to prepare mesostructured silica [41]. Since the interaction of TMV with certain divalent metal cations can lead to ordered aggregation of the virus [62], metal cations were introduced into the silica sol-gel process in an attempt to order the TMV in the gel. As shown in Fig. 5(b), when $\mathrm{CdSO}_{4}$ was added into the silica precursor, aligned arrays of TMV were obtained. Upon calcination at $500{ }^{\circ} \mathrm{C}$ for $2 \mathrm{~h}$, mesoporous silica was produced maintaining the channel-like structure. The $\mathrm{N}_{2}$ adsorption-desorption isotherm of the prepared mesoporous silica after calcination showed a typical Type IV pattern, characteristic of many mesoporous materials, with a BET surface area of $329 \mathrm{~m}^{2} / \mathrm{g}$ (Fig. S-3 in the ESM). Finally, long fibers of polyanilinecoated TMV were used as the template material in an attempt to obtain long channel-like structures within the silica. Our previous study showed that TMV can self-assemble into one-dimensional long fiber structures when assisted by aniline polymerization $[26,63,64]$. The as-prepared fibers have uniform diameter with lengths reaching several $\mu \mathrm{m}$ (Fig. 5(c)). As shown in Fig. 5(d), with the long fibers as a template, silica composites were readily prepared, with the long fibers being well-dispersed in the silica gel and retaining their original shape. 


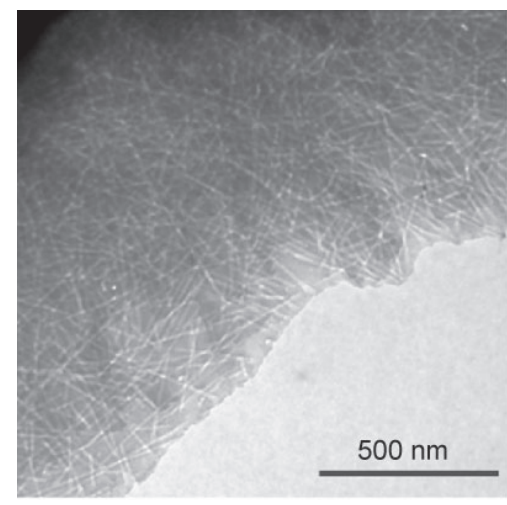

(a)

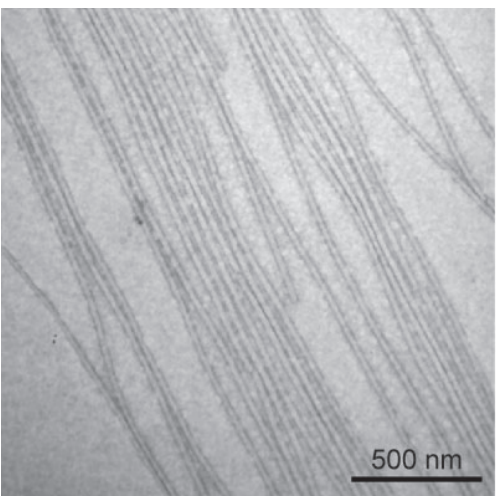

(c)

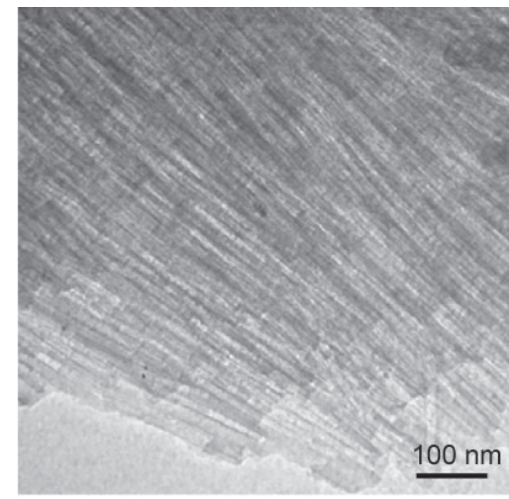

(b)

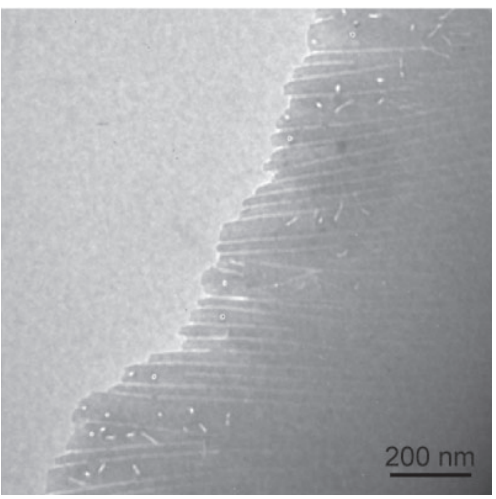

(d)

Figure 5 TEM images of (a) TMV/silica composites with random distribution; (b) $\mathrm{Cd}^{2+}$-directed parallel alignment of TMV inside silica; (c) long fibers of polyaniline/TMV; (d) polyaniline/TMV/silica composites

\section{Conclusions}

In summary, a practical sol-gel process has been developed, in which encapsulation of a variety of bionanoparticles was performed in such a way that the particles maintained their integrity and morphology. Upon calcination, mesoporous silica with monodisperse pores was produced, with the shape and surface morphology of the bionanoparticles replicated inside the silica. The structures of these materials were confirmed by TEM, SAXS, SEM-EDAX, and $\mathrm{N}_{2}$ adsorptiondesorption analysis. The structure of the internal pores was dictated by the bionanoparticle used as the template. Additionally, the surface features of the bionanoparticles at the nanometer or subnanometer scale can likely make major contribution to the surface area of the resultant mesoporous silica; therefore, it may be possible to fine-tune the cavity and shape of the pores at the sub-nanometer scale by further manipulating the surface of the bionanoparticle. Moreover, it is possible to deliver different inorganic nanoparticles inside the silica matrix if modified ferritins are used. This study is expected to ultimately lead to functional composite materials and mesoporous silica with well-defined interior structures and chemistries.

\section{Acknowledgements}

We are grateful for financial support from NSFDMR-0706431, NSF Career Award, the Camille Dreyfus Teacher-Scholarship, the Alfred P. Sloan Foundation, US ARO MURI program, and the W. M. Keck Foundation. The SAXS data were obtained at beamline X21 of the National Synchrotron Light Source, Brookhaven National Laboratory. The use of NSLS was supported by the U.S. Department 
of Energy, Office of Science, Office of Basic Energy Sciences, under Contract No. DE-AC02-98CH10886.

\section{Electronic Supplementary Material: Nitrogen} adsorption-desorption isotherms for TYMV- and TMV-templated mesoporous silica, and the TEM image of ferritin-templated silica composite materials are available in the online version of this article at http://dx.doi.org/10.1007/s12274-009-9043-6 and are accessible free of charge.

\section{References}

[1] Ying, J. Y.; Mehnert, C. P.; Wong, M. S. Synthesis and applications of supramolecular-templated mesoporous materials. Angew. Chem. Int. Ed. 1999, 38, 56-77.

[2] Davis, M. E. Ordered porous materials for emerging applications. Nature 2002, 417, 813-821.

[3] Yiu, H. H. P.; Wright, P. A. Enzymes supported on ordered mesoporous solids: A special case of an inorganicorganic hybrid. J. Mater. Chem. 2005, 15, 3690-3700.

[4] Hartmann, M. Ordered mesoporous materials for bioadsorption and biocatalysis. Chem. Mater. 2005, 17, 4577-4593.

[5] Lu, Y. F.; Yang, Y.; Sellinger, A.; Lu, M. C.; Huang, J. M.; Fan, H. Y.; Haddad, R.; Lopez, G.; Burns, A. R.; Sasaki, D. Y.; Shelnutt, J.; Brinker, C. J. Self-assembly of mesoscopically ordered chromatic polydiacetylene/silica nanocomposites. Nature 2001, 410, 913-917.

[6] Yang, P. D.; Zhao, D. Y.; Chmelka, B. F.; Stucky, G. D. Triblock-copolymer-directed syntheses of large-pore mesoporous silica fibers. Chem. Mater. 1998, 10, 20332036.

[7] Mal, N. K.; Fujiwara, M.; Tanaka, Y. Photocontrolled reversible release of guest molecules from coumarinmodified mesoporous silica. Nature 2003, 421, 350353.

[8] El-Safty, S. A. Review on the key controls of designer copolymer-silica mesophase monoliths (HOM-type) with large particle morphology, ordered geometry and uniform pore dimension. J. Porous Mater. 2008, 15, 369 $-387$.

[9] Sanchez, C.; Boissiere, C.; Grosso, D.; Laberty, C.; Nicole, L. Design, synthesis, and properties of inorganic and hybrid thin films having periodically organized nanoporosity. Chem. Mater. 2008, 20, 682-737.
[10] Wan, Y.; Shi, Y. F.; Zhao, D. Y. Supramolecular aggregates as templates: Ordered mesoporous polymers and carbons. Chem. Mater. 2008, 20, 932-945.

[11] Matos, J. R.; Kruk, M.; Mercuri, L. P.; Jaroniec, M.; Zhao, L.; Kamiyama, T.; Terasaki, O.; Pinnavaia, T. J.; Liu, Y. Ordered mesoporous silica with large cage-like pores: Structural identification and pore connectivity design by controlling the synthesis temperature and time. J. Am. Chem. Soc. 2003, 125, 821-829.

[12] Fan, J.; Yu, C. Z.; Lei, J.; Zhang, Q.; Li, T. C.; Tu, B.; Zhou, W. Z.; Zhao, D. Y. Low-temperature strategy to synthesize highly ordered mesoporous silicas with very large pores. J. Am. Chem. Soc. 2005, 127, 1079410795.

[13] Douglas, T.; Young, M. Viruses: Making friends with old foes. Science 2006, 312, 873-875.

[14] Lee, L. A.; Wang, Q. Adaptations of nanoscale viruses and other protein cages for medical applications. Nanomedicine 2006, 2, 137-149.

[15] Kramer, R. M.; Li, C.; Carter, D. C.; Stone, M. O.; Naik, R. R. Engineered protein cages for nanomaterial synthesis. J. Am. Chem. Soc. 2004, 126, 13282-13286.

[16] Meldrum, F. C.; Heywood, B. R.; Mann, S. Magnetoferritin: In vitro synthesis of a novel magnetic protein. Science 1992, 257, 522-523.

[17] Flenniken, M. L.; Willits, D. A.; Brumfield, S.; Young, M. J.; Douglas, T. The small heat shock protein cage from methanococcus jannaschii is a versatile nanoscale platform for genetic and chemical modification. Nano Lett. 2003, 3, 1573-1576.

[18] Seebeck, F. P.; Woycechowsky, K. J.; Zhuang, W.; Rabe, J. P.; Hilvert, D. A simple tagging system for protein encapsulation. J. Am. Chem. Soc. 2006, 128, 45164517.

[19] Domingo, G. J.; Orru, S.; Perham, R. N. Multiple display of peptides and proteins on a macromolecular scaffold derived from a multienzyme complex. J. Mol. Biol. 2001, 305, 259-267.

[20] Paavola, C. D.; Chan, S. L.; Li, Y.; Mazzarella, K. M.; McMillan, R. A.; Trent, J. D. A versatile platform for nanotechnology based on circular permutation of a chaperonin protein. Nanotechnology 2006, 17, $1171-$ 1176.

[21] Campos, S. K.; Barry, M. A. Current advances and future challenges in adenoviral vector biology and targeting. Curr. Gene Ther. 2007, 7, 189-204. 
[22] Manchester, M.; Singh, P. Virus-based nanoparticles (VNPs): Platform technologies for diagnostic imaging. Adv. Drug Deliv. Rev. 2006, 58, 1505-1522.

[23] Ramqvist, T.; Andreasson, K.; Dalanis, T. Vaccination, immune and gene therapy based on virus-like particles against viral infections and cancer. Expert Opin. Biol. Ther. 2007, 7, 997-1007.

[24] Canizares, M. C.; Nicholson, L.; Lomonossoff, G. P. Use of viral vectors for vaccine production in plants. Immunol. Cell Biol. 2005, 83, 263-270.

[25] Streatfield, S. J. Oral hepatitis B vaccine candidates produced and delivered in plant material. Immunol. Cell Biol. 2005, 83, 257-262.

[26] Niu, Z.; Bruckman, M.; Kotakadi, V. S.; He, J.; Emrick, T.; Russell, T. P.; Yang, L.; Wang, Q. Study and characterization of tobacco mosaic virus head-to-tail assembly assisted by aniline polymerization. Chem. Commun. 2006, 3019-3021.

[27] Mao, C.; Solis, D. J.; Reiss, B. D.; Kottmann, S. T.; Sweeney, R. Y.; Hayhurst, A.; Georgiou, G.; Iverson, B.; Belcher, A. M. Virus-based toolkit for the directed synthesis of magnetic and semiconducting nanowires. Science 2004, 303, 213-217.

[28] Niu, Z.; Bruckman, M.; Harp, B.; Mello, C. M.; Wang, Q. Bacteriophage M13 as scaffold for preparing conductive polymeric composite fibers. Nano Res. 2008, 1, 235241.

[29] Rong, J. H.; Lee, L. A.; Li, K.; Harp, B.; Mello, C. M.; Niu, Z. W.; Wang, Q. Oriented cell growth on self-assembled bacteriophage M13 thin films. Chem. Commun. 2008, 5185-5187.

[30] Kaur, G.; Valarmathi, M. T.; Potts, J. D.; Wang, Q. The promotion of osteoblastic differentiation of rat bone marrow stromal cells by a polyvalent plant mosaic virus. Biomaterials 2008, 29, 4074-4081.

[31] Li, T.; Niu, Z. W.; Emrick, T.; Russell, T. R.; Wang, Q. Core/shell biocomposites from the hierarchical assembly of bionanoparticles and polymer. Small 2008, 4, 16241629.

[32] Lee, L. A.; Niu, Z.; Wang, Q. Viruses and virus-like protein assemblies - Chemically programmable nanoscale building blocks. Nano Res. accepted.

[33] Rong, J.; Oberbeck, F.; Wang, X.; Li, X.; Oxsher, J.; Niu, Z.; Wang, Q. Tobacco mosaic virus templated synthesis of one dimensional inorganic/polymer hybrid fibres. J. Mater. Chem. 2009, 19, 2841-2845.
[34] Lin, Y.; Boker, A.; He, J.; Sill, K.; Xiang, H.; Abetz, C.; Li, X.; Wang, J.; Emrick, T.; Long, S.; Wang, Q.; Balazs, A.; Russell, T. P. Self-directed self-assembly of nanoparticle/ copolymer mixtures. Nature 2005, 434, 55-59.

[35] Russell, J. T.; Lin, Y.; Böker, A.; Long, S.; Carl, P.; Zettl, H.; He, J.; Sill, K.; Tangiraia, R.; Emrick, T.; Littrell, K.; Thiyagarajan, P.; Cookson, D.; Fery, A.; Wang, Q.; Russell, T. P. Self-assembly and cross-linking of bionanoparticles at liquid-liquid interfaces. Angew. Chem. Int. Ed. 2005, 44, 2420-2426.

[36] Avnir, D.; Coradin, T.; Lev, O.; Livage, J. Recent bioapplications of sol-gel materials. J. Mater. Chem. 2006, 16, 1013-1030.

[37] Ferrer, M. L.; del Monte, F.; Levy, D. A novel and simple alcohol-free sol-gel route for encapsulation of labile proteins. Chem. Mater. 2002, 14, 3619-3621.

[38] Gill, I.; Ballesteros, A. Encapsulation of biologicals within silicate, siloxane, and hybrid sol-gel polymers: An efficient and generic approach. J. Am. Chem. Soc. 1998, 120, 8587-8598.

[39] Lan, E. H.; Dunn, B.; Valentine, J. S.; Zink, J. I. Encapsulation of the ferritin protein in sol-gel derived silica glasses. J. Sol-Gel Sci. Techn. 1996, 7, 109-116.

[40] Tartaj, P.; Gonzalez-Carreno, T.; Ferrer, M. L.; Serna, C. J. Metallic nanomagnets randomly dispersed in spherical colloids: Toward a universal route for the preparation of colloidal composites containing nanoparticles. Angew. Chem. Int. Ed. 2004, 43, 6304-6307.

[41] Fowler, C. E.; Shenton, W.; Stubbs, G.; Mann, S. Tobacco mosaic virus liquid crystals as templates for the interior design of silica mesophases and nanoparticles. Adv. Mater. 2001, 13, 1266-1269.

[42] Royston, E.; Lee, S. Y.; Culver, J. N.; Harris, M. T. Characterization of silica-coated tobacco mosaic virus. J. Coll. Int. Sci. 2006, 298, 706-712.

[43] Klug, A.; Finch, J. T.; Franklin, R. E. Structure of turnip yellow mosaic virus. Nature 1957, 179, 683-684.

[44] Canady, M. A.; Larson, S. B.; Day, J.; McPherson, A. Crystal structure of turnip yellow mosaic virus. Nat. Struct. Biol. 1996, 3, 771-781.

[45] Wang, Q.; Raja, K. S.; Janda, K. D.; Lin, T. W.; Finn, M. $\mathrm{G}$. Blue fluorescent antibodies as reporters of steric accessibility in virus conjugates. Bioconjugate Chem. 2003, 14, 38-43.

[46] Wang, Q.; Lin, T. W.; Johnson, J. E.; Finn, M. G. Natural supramolecular building blocks: Cysteine-added mutants 
of cowpea mosaic virus. Chem. Biol. 2002, 9, 813-819.

[47] Wang, Q.; Kaltgrad, E.; Lin, T. W.; Johnson, J. E.; Finn, M. G. Natural supramolecular building blocks: Wild-type cowpea mosaic virus. Chem. Biol. 2002, 9, 805-811.

[48] Wang, Q.; Chan, T. R.; Hilgraf, R.; Fokin, V. V.; Sharpless, K. B.; Finn, M. G. Bioconjugation by copper(I)-catalyzed azide-alkyne [3+2] cycloaddition. J. Am. Chem. Soc. 2003, 125, 3192-3193.

[49] Klug, A. The tobacco mosaic virus particle: Structure and assembly. Philos. Trans. R. Soc. B 1999, 354, 531-535.

[50] Shenton, W.; Douglas, T.; Young, M.; Stubbs, G.; Mann, S. Inorganic-organic nanotube composites from template mineralization of tobacco mosaic virus. Adv. Mater. 1999, 11, 253-256.

[51] Fonoberov, V. A.; Balandin, A. A. Phonon confinement effects in hybrid virus-inorganic nanotubes for nanoelectronic applications. Nano Lett. 2005, 5, 1920 1923.

[52] Knez, M.; Sumser, M.; Bittner, A. M.; Wege, C.; Jeske, H.; Martin, T. P.; Kern, K. Spatially selective nucleation of metal clusters on the tobacco mosaic virus. Adv. Funct. Mater. 2004, 14, 116-124.

[53] Yi, H.; Nisar, S.; Lee, S. Y.; Powers, M. A.; Bentley, W. E.; Payne, G. F.; Ghodssi, R.; Rubloff, G. W.; Harris, M. T.; Culver, J. N. Patterned assembly of genetically modified viral nanotemplates via nucleic acid hybridization. Nano Lett. 2005, 5, 1931-1936.

[54] Yi, H.; Rubloff, G. W.; Culver, J. N. TMV microarrays: Hybridization-based assembly of DNA-programmed viral nanotemplates. Langmuir 2007, 23, 2663-2667.

[55] Tan, W. S.; Lewis, C. L.; Horelik, N. E.; Pregibon, D. C.; Doyle, P. S.; Yi, H. Hierarchical assembly of viral nanotemplates with encoded microparticles via nucleic acid hybridization. Langmuir 2008, 24, 12483-12488.
[56] Balci, S.; Leinberger, D. M.; Knez, M.; Bittner, A. M.; Boes, F.; Kadri, A.; Wege, C.; Jeske, H.; Kern, K. Printing and aligning mesoscale patterns of tobacco mosaic virus on surfaces. Adv. Mater. 2008, 20, 2195-2200.

[57] Wong, K. K. W.; Douglas, T.; Gider, S.; Awschalom, D. D.; Mann, S. Biomimetic synthesis and characterization of magnetic proteins (magnetoferritin). Chem. Mater. 1998, 10, 279-285.

[58] Douglas, T.; Dickson, D. P. E.; Betteridge, S.; Charnock, J.; Garner, C. D.; Mann, S. Synthesis and structure of an iron(III) sulfide-ferritin bioinorganic nanocomposite. Science 1995, 269, 54-57.

[59] Stark, V.; Douglas, T. Nanophase cobalt oxyhydroxide mineral synthesized within the protein cage of ferritin. Inorg. Chem. 1999, 39, 1828-1830.

[60] Kuang, D. B.; Brezesinski, T.; Smarsly, B. Hierarchical porous silica materials with a trimodal pore system using surfactant templates. J. Am. Chem. Soc. 2004, 126, 10534-10535.

[61] Svergun, D. I.; Koch, M. H. J. Small-angle scattering studies of biological macromolecules in solution. Rep. Prog. Phys. 2003, 66, 1735-1782.

[62] Nedoluzhko, A.; Douglas, T. Ordered association of tobacco mosaic virus in the presence of divalent metal ions. J. Inorg. Biochem. 2001, 84, 233-240.

[63] Niu, Z. W.; Bruckman, M. A.; Li, S. Q.; Lee, L. A.; Lee, B.; Pingali, S. V.; Thiyagarajan, P.; Wang, Q. Assembly of tobacco mosaic virus into fibrous and macroscopic bundled arrays mediated by surface aniline polymerization. Langmuir 2007, 23, 6719-6724.

[64] Niu, Z.; Liu, J.; Lee, L. A.; Bruckman, M. A.; Zhao, D.; Koley, G.; Wang, Q. Biological templated synthesis of water-soluble conductive polymeric nanowires. Nano Lett. 2007, 7, 3729-3733. 